\title{
Exploration and practice of the training mode of internationalized applied talents
}

\section{- - Northwestern Polytechnical University, Ming De College HND CSCSE-SQA project}

\author{
Dingyi $\mathrm{Wu}^{1, \mathrm{a}}$, Yuren $\mathrm{Li}^{2, \mathrm{~b}}$, Lingsheng $\mathrm{Gou}^{3, \mathrm{c}^{*}}$ Xin $\mathrm{Di}^{4, \mathrm{~d}}$ and Xizhe $\mathrm{Zhi}^{5, \mathrm{e}}$ \\ ${ }^{1}$ Northwestern Polytechnical University, Ming De College of the School office, ChangAn, Xi'An, \\ ShanXi, China \\ ${ }^{2}$ Northwestern Polytechnical University, Ming De College of the School office, ChangAn, Xi'An, \\ ShanXi, China \\ ${ }^{3}$ Northwestern Polytechnical University, Ming De College of the public education Department, \\ ChangAn, Xi'An, ShanXi, China \\ ${ }^{4}$ Northwestern Polytechnical University, Ming De College of the Dean's Office ,ChangAn, Xi'An, \\ ShanXi, China \\ ${ }^{5}$ Northwestern Polytechnical University, Ming De College of the Dean's Office, ChangAn, Xi'An, \\ ShanXi, China

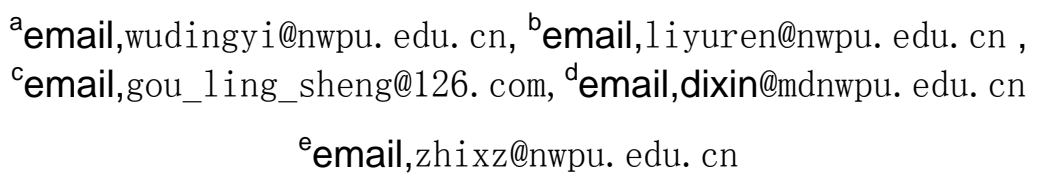 \\ *Corresponding author,GouLingsheng
}

\begin{abstract}
Key words: Internationalization; applied talents; training model
Abstract.In order to adapt to the trend of the internationalization of higher education, training with international vision, familiar with international rules, to participate in international affairs and international competition of international talents, this paper is based on Northwestern Polytechnical University of MingDe College CSCSE-SQA HND project, aiming at the construction of internationalized talents training target, the basic ideas and methods, improving training applied talents of our country the international system and mechanism, enhancing China's international talent cultivation quality and competitive ability.
\end{abstract}

\footnotetext{
国际化应用型人才培养模式的探索与实践 - 一西北工业大学明德学院CSCSE-SQA HND项目 吴丁毅 $1, \mathrm{a}$,李玉忍 ${ }^{2, b}$,苟灵生 ${ }^{3, \mathrm{c} *}$,邸金金 $4, \mathrm{~d}$,支希哲 ${ }^{5, \mathrm{e}}$

1西北工业大学明德学院学院办公室, 长安, 西安, 陕西, 中国

2西北工业大学明德学院学院办公室, 长安, 西安, 陕西, 中国

${ }^{3}$ 西北工业大学明德学院公共教育系, 长安, 西安, 陕西, 中国

${ }^{4}$ 西北工业大学明德学院教务科研部, 长安, 西安, 陕西, 中国

${ }^{5}$ 西北工业大学明德学院教务科研部, 长安, 西安, 陕西, 中国

通讯作者, 荷灵生
}

关键词：国际化；应用型人才；培养模式；探索 
中文摘要：为适应高等教育国际化趋势, 培养具有国际视野, 通晓国际规则, 能够参与 国际事务和国际竞争的国际化应用型人才, 本文以西北工业大学明德学院CSCSE-SQA HND 项目, 所构建的国际化应用型人才培养的目标定位、基本思路和方法措施为例, 以期完善我 国应用型人才培养的国际化体系和机制，提升我国国际化人才培养的质量和竞争能力。

\section{1.引言}

面对高等教育国际化为我们带来的机遇和挑战, 西北工业大学明德学院抢抓机遇, 大力 推动国际化应用型人才培养模式的国际化进程, 先后与美国、德国、英国、日本、荷兰、新 加坡、台湾、香港等国家或地区的四十多所院校签订了 “ $2+2 ” 、 “ 2+2+1 ” 、$ 短期留学、暑 期学校、带薪实习等合作和交流项目, 每年已经有 100 余名学生参与了国际化应用型人才培养, 有相当一部分已经获得学位, 获得高一级的学习机会, 有的已经在国际大公司或跨国公司就 业。其中西北工业大学明德学院2014年派往德国柏林玛丽蒂姆酒店带薪实习的学生受到了来 德国访问的李克强总理的接见。北京时间2014年10月10日，国务院总理李克强抵达德国柏林， 主持第三轮中德政府磋商并访问德国, 在下榻的德国柏林玛丽蒂姆酒店巧遇在此实习的我院 德语专业的张逸晗、段然两位同学, 并亲切接见了她们, 勉励她们要好好工作, 从基层做起。

通过该项目的研究，我们将从几年的实践中总结经验，完善我们的国际化应用型人才的 培养模式, 管理模式、机制和体制。并将其上升到理论, 有利于推广和应用, 由于促进国际 化应用型人才的培养。

\section{2.探索国际化应用型人才培养目标定位：理念}

所谓应用型人才是指能将专业知识和技能应用于所从事的专业社会实践的一种专门的人 才类型, 是熟练掌握社会生产或社会活动一线的基础知识和基本技能, 主要从事一线生产的 技术或专业人才。对于应用型本科院校培养的人才而言, 一方面, 应用型人才要具有社会生 产一线的基础理论知识, 基本的理论基础扎实, 另一方面, 应用型人才要熟练掌握生产和社 会活动一线的基本技能, 动手操作能力强, 进入用人单位以后能迅速转变角色, 独立承担生 产和社会活动一线的工作任务。随着世界科学技术的飞速发展, 世界各国交流与合作空前频 繁。在这样的宏观背景下, 高等教育国际化的发展和变革日新月异。面对高等教育国际化为 我们带来的机遇和挑战，我们必须抢抓机遇，树立国际化观念，变本土教育为国际化教育， 培养学生具有国际视野的现代化、国际化的人才, 培养专业知识、外语能力、跨文化交际能 力、综合素质、工程实践能力、团队协作能力, 自主式学习, 注重创新素质, 着力培养具有 国际意识、合作精神、创新能力的国际化应用型人才。 
在国际化应用型人才培养的过程中, 需要解决的是国际化对应用型人才培养与需求的结 构性矛盾, 我们必须着眼于国际市场, 树立市场意识, 根据办学总体定位和办学思路, 科学、 合理地调整、设置专业, 加快发展蕴藏着巨大经济潜力的新兴学科、交叉学科、边缘学科。 加大国际化应用型人才培养的力度, 构建新的应用型人才培养体系。改革人才培养模式, 以 更高的角度、更广阔的视野, 构建与国际接轨的课程体系。建立与国际接轨的教学运行与管 理机制。认真研究教育开放和国际合作的有关政策, 建立和健全有关的法律、法规, 使得我 们的办学体制、培养模式、课程体系、教学方法和内容与国际接轨。

\section{3.构建国际化培养模式和课程体系基本思路：方法}

\section{1引进海外课程结构与体系（如SQA HND项目）}

按照更开放、更灵活、国际化的思路，培养基础扎实、掌握国际知识、英语水平、实务 能力的国际化专业人才, 积极与国外多所大学建立长期、稳定的合作。遵循国家我国高等教 育中长期教育改革和发展规划纲要的规划, 大力开展教学模式创新, 积极引进海外知名大学 的课程结构与体系（如SQA HND项目），探索多种形式的境外大学深度合作模式和课程体系 建设, 共同培养国际化专业人才。在 “特色发展” 和 “品牌意识” 加快推进 “宽领域、多渠 道、上水平、创一流” 的前进步伐, 打造具有国际化办学特色的人才培养模式。学习国外先 进的教育理念和教学模式, 坚持教育教学发展创新, 以国际化人才培养为龙头、课程建设为 核心、大力发展特色国际教育。

为学生提供严格的国际教育环境, 为他们的出国深造或在国际组织中获得职位做准备。 从全球范围内获得的最好的知识和实践经验提供给学生为目标, 我们建立一个强大的国际视 野具有政府背景的海外留学CSCSE-SQA HND项目。2004年西北工业大学经陕西省教育厅批 准, 中国教育部留学服务中心审核, 苏格兰学历管理委员会授权, 在西北地区设立了唯一的 CSCSE-SQA HND项目教学示范中心, 办学地点设在西北工业大学明德学院。该项目在明德 学院已成功运营十余年, 在教学、管理方面经验丰富并逐步形成科学化模式, 教师团队及管 理团队均能为学生提供优质服务。项目采用的是 $3+1$ 的教学模式, 这种模式使学生更易于接受 国外的教育理念、学习模式以及生活环境, 同时最大程度降低了出国留学的经济成本。项目 学生在国内三年的学习均由苏格兰学历管理委员进行全程教学管理和质量监控。第四年学生 出国留学由教育部留学服务中心设专人为学生提供一站式留学咨询和签证指导服务。

办学总体目标: 修订和评估现有的课程, 以确保它们符合国际应用型人才的高要求; 安 排访问学者为学生做讲座, 以便学生可以了解到在知识和实践方面最新的发展; 与国外的其 他院校签订协议, 以保证有志于在国外接受教育的学生能够成行; 加强学生知识和能力的培 
养, 使他们能够在中国或者其他国家的国际组织工作; 请国外的学生来与国际学生一起实习, 学习, 生活, 使国际化应用型学生能够接触到国外的习俗和惯例; 建立全英文的教学研究基 地, 使我们能够在国际层面上参与专业讨论, 通过采用国际准则, 使国际化学生能获得国际 认可的认证机构的认证；并进一步改善其国际贸易和国际商务关系。

根据国外高校课程设计, 部分课程采用一流大学通用的英文版教材, 教学内容及方法与 国际接轨。课堂教学分全英、双语授课方式。具体表现为: 聘请外教的, 一律为全英教学方 式。而对于一些开放性较强的专业课程, 一般采取全英或者双语授课的方式授课。

在专业培养上, 将学生培养成为充分理解并在未来几年将充分被采纳的国际准则, 确保 授课内容和方法能反映目前国际上的知识, 实践和政策, 确保专业结合了 “一带一路” 走势 等热点。此外, 考虑到学生的接受能力, 为教授专业课的外教配以助教协助教学, 以确保学 生有英语学习环境的同时能够掌握课程的内容。

\section{2形成了普及化的导学机制}

在国际化办学中形成了普及化的导学机制, 通过一个测评系统, 对国际化应用型学生学 习风格和职业倾向测评, 通过测评结果, 通过导师制一一对学生进行指导。一个是通过建立 解决了地方院校传统人才培养定位与国际化人才需求的不适应问题。一个是通过构建纵向梯 次递进, 横向相互融合的课程群, 解决普及化生源背景下, 地方人才培养中, 应用实践两种 能力薄弱相互脱节的问题。最后是通过解决了学生学习动力与投入不足, 职业规划目标不清 的问题。取得的主要成效。一是英语教学分级分类改革成效比较明显。学院把外语教学作为 教学工作的重点, 大力开展多种形式的英语学习, 如早读、英语比赛、英语讲演、雅思和托 福培训等, 旨在营造校园国际化氛围, 推动教育国际化的发展。一是我们从2015年开始对全 院学生进行英语月考分级教学。对部分国际化化专业进行全英语班的分类教学, 使全院学生 英语不及格的学生四级英语一次通过率从提高了百分点。并获得了国家协会主办国际商务谈 判大赛团体奖项。

\section{4 .建立多种形式的联合培养方法措施：途径}

\section{1以构建两主线、三结合、四平台的人才培养框架体系}

两条主线是指英语应用能力主线, 实践能力的主线。三个结合是指理论教学与实践教学 相结合, 专业实践与社会相结合, 学生专业学习与教师科研活动相结合。四个平台是英语展 示交流平台, 英语实践教学平台, 国际实务拓展平台和网络教学平台。第二个情况是构建英 语应用能力的培养是沿着基础英语, 商务基本英语, 商务专业英语、国外综合英语梯次增进 和专业英语课程。实践能力培养是从信息技术应用及活动专业应用实战。通20多门双语课, 
实现了英语课程国际化课程的交叉, 实现了专业能力与英语专业应用能力的结合, 并且通过 海外实习、实践, 和海外继续学习深造, 增强了应用实践能力的结合。

\section{2以 “双语教师” 为抓手，对外 “引智”，对内 “培植”，提升质量}

积极面向国内及海外招聘、面试国内外 “双语教师” 、行政人员。并外派教师、行政人 员到国外或国内各地接受与其专业教学、办公相关的培训, 使其更快适应国际化教学及办公 标准, 提高自身素质及国际商学院整体素质及地位。制定持续性教学及行政培训计划, 提高 教学能力和水平, 提升整体教学质量。建立师资即有系统的引进高素质人才、与专业认证方 向一致、带动教研及科研风气。积极聘请高水平的外教, 重视师资队伍的建设。课堂上, 通 过活动激发模式, 让学生主动融入课堂教学, 引发深层次的思考。教学方式上遵循 “活动+ 分享+提升+能力” 的原则, 培养学生的市场预测与决策能力, 以达到学以致用的目的。这种 新颖的教学方式有利于提高和强化逻辑思维能力, 轻松的课堂气氛, 大大调动了同学们的学 习积极性, 让同学们有更多的机会表达自我、展示自我、分享智慧、快乐学习, 有助于提高 同学们分析问题、解决问题能力。

4.3以 “国际化办学” 宗旨, 为给学生提供一个严谨的国际教育环境, 来培养他们继续到 国外深造或任职的国际人才

\subsection{1加强产学研合作, 强化国际化人才培养效应}

为适应国际化应用型人才培养的需求, 加大投入, 打造精品, 注重交流, 学以致用, 广 泛开展 “校企” 合作, 与国内许多高校积极开展何跨国公司开展合作, 发展国际间 “校企” 合作, 如建立实验教学平台和人才培养中心, 发挥学校人才、资源优势。通过与跨国公司的 合作, 为学生提供更多的实习机会。通过参与校企合作项目及国际研发, 不仅使学生得到了 学习和锻炼的机会, 开阔了学生的学习和研究视野, 提高了本身的适应能力, 如组织学生参 加国外的实习、大型展会服务项目, 使专业实践与社会服务相结合。通过举办英语文化节, 英语竞赛等活动, 营造浓厚的英语学习氛围, 建立了实践教学示范中心和 30 个校外人才培养 基地。

\subsection{2加强跨文化交流, 提高自身的语言表达能力和强化专业知识的学习}

培养学生遇到语言障碍、专业知识缺乏、文化差异的情况下, 如何保证分工明确、适当 转换心态、角度去学习和沟通、提高团结协作增强跨文化交流中相互包容的态度。通过召开 家长会, 让家长们能更加全面地了解国际化应用型人才的发展前景和现状, 及时地让家长们 掌握学生在校的表现, 介绍教学计划、课程安排以及有效指导学习方法, 与家长共同探讨学 生培养模式。组织学生参加《职业规划》、《大学生心理适应》、《创业管理》讲座、完成 
心理测评、职业储备、完善心理健康体系外, 还积极组织学生座谈会, 为学生提供学生出国 辅导，使流程制度化、服务个人化、辅导人性化。

\section{4以 “SQA HND项目”为平台，凝练特色，办出水平，扩大影响}

为提高在国际上的知名度和地位, 使学生和教师能受到国际化标准的教学及考核, 着手 进行申请筹备一系列国际认证。选派优秀教师赴专业机构进行国际认可的ACCA课程培训, 按照国际认证机构提出的认证标准进行课程设置、教学模式、教学资料、师资及学生培养。

为使教师更好地了解、学习国内外优秀的教学模式及教学方法, 加强教师、学生的跨文 化交际, 同时培养学生的创新能力, 将学生的竞赛、创新活动组织和协调起来, 选派教师参 加国际教学年会和了解国际前沿资讯。通过国际商业礼仪活动, 使得学生的整体形象和综合 素质, 掌握相关国际礼仪知识提高。以课程案例分析为实例, 通过视频内容、分析调研、市 场预测等手段，使学生国际策划能力有所提高。以各种模拟联合国创新团队、创新社团等， 参加学生组织国内外创新、创业、观摩活动, 倡导第一课堂和第二课堂相互补充。CSCSE-SQA HND项目的办学水平和办学能力逐步扩大。

致谢: 本文为2015年陕西省教育厅教改项目《国际化应用型人才培养模式的研究与实践》 （陕教高〔2015〕21号）的阶段性成果之一。

\section{References:}

[1] Pan Mao yuan. I see the positioning problem [J]. Journal of applied undergraduate colleges education development research, pp. 34-36200-7 (7-8 a).

[2] Tang Mobing. Local commercial colleges and universities should take the responsibility of training applied talents [J]. And for the purpose of training applied talents of higher education in China, pp. 28-29200-6 (20).

[3] Li ling.international business exploration and practice of applied talents training mode [J]. Value engineering, pp. 127-128201-4 (5).

[4] QiuYun. International applied creative talents evaluation system building [J]. Journal of ningbo university (social science edition), pp. 76-79200, 7 (6).

[6] HuangYing, Lv Hongfen Fu Changluan. The internationalization of professional personnel training mode research review [J]. Journal of Ning Bo university (education science edition), pp. 78-81201, 2 (2).

[7]ZhongGaozheng. Business personnel training of rational thinking [J]. Journal of the national business (economic theory research), pp. 50-51208 (19).

[8] national medium and long-term education reform and development plan (2010-2020) [EB/OL] HTTP: / / http://www.gov.cn/jrzg / 2010-07/29 / content_1667143. HTM, check the date of 2016-5-1. 